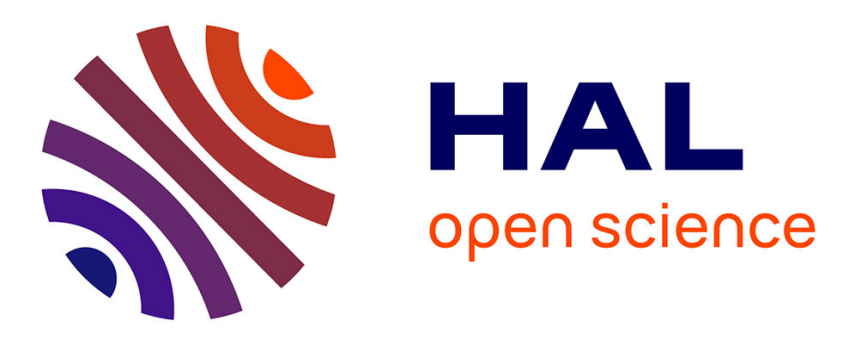

\title{
New penicillin susceptibility breakpoints for and their effects on susceptibility categorisation in Germany (1992-2008)
}

\author{
Matthias Imöhl, Ralf René Reinert, Mark van Der Linden
}

\section{To cite this version:}

Matthias Imöhl, Ralf René Reinert, Mark van Der Linden. New penicillin susceptibility breakpoints for and their effects on susceptibility categorisation in Germany (1992-2008). International Journal of Antimicrobial Agents, 2009, 34 (3), pp.271. 10.1016/j.ijantimicag.2009.03.022 . hal-00556342

\section{HAL Id: hal-00556342 \\ https://hal.science/hal-00556342}

Submitted on 16 Jan 2011

HAL is a multi-disciplinary open access archive for the deposit and dissemination of scientific research documents, whether they are published or not. The documents may come from teaching and research institutions in France or abroad, or from public or private research centers.
L'archive ouverte pluridisciplinaire HAL, est destinée au dépôt et à la diffusion de documents scientifiques de niveau recherche, publiés ou non, émanant des établissements d'enseignement et de recherche français ou étrangers, des laboratoires publics ou privés. 


\section{Accepted Manuscript}

Title: New penicillin susceptibility breakpoints for Streptococcus pneumoniae and their effects on susceptibility categorisation in Germany (1992-2008)

Authors: Matthias Imöhl, Ralf René Reinert, Mark van der Linden

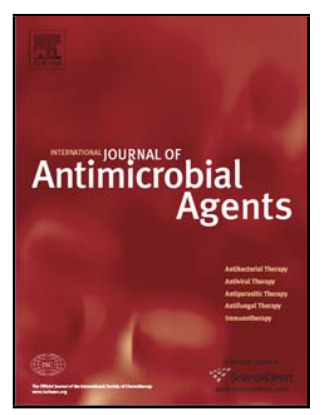

PII:

DOI:

Reference:

S0924-8579(09)00180-0

ANTAGE 3027

To appear in: International Journal of Antimicrobial Agents

Received date: $\quad 27-1-2009$

Revised date: $\quad 31-3-2009$

Accepted date: $\quad 31-3-2009$

Please cite this article as: Imöhl M, Reinert RR, van der Linden M, New penicillin susceptibility breakpoints for Streptococcus pneumoniae and their effects on susceptibility categorisation in Germany (1992-2008), International Journal of Antimicrobial Agents (2008), doi:10.1016/j.ijantimicag.2009.03.022

This is a PDF file of an unedited manuscript that has been accepted for publication. As a service to our customers we are providing this early version of the manuscript. The manuscript will undergo copyediting, typesetting, and review of the resulting proof before it is published in its final form. Please note that during the production process errors may be discovered which could affect the content, and all legal disclaimers that apply to the journal pertain. 


\section{New penicillin susceptibility breakpoints for Streptococcus pneumoniae and their effects on susceptibility} categorisation in Germany (1992-2008)

Matthias Imöhl ${ }^{a, *}$, Ralf René Reinert ${ }^{b}$, Mark van der Linden ${ }^{a}$

a Institute of Medical Microbiology, National Reference Center for Streptococci, University Hospital (RWTH), Pauwelsstr. 30, Aachen, Germany

${ }^{\mathrm{b}}$ Wyeth Vaccines Research, Paris La Défense, Paris, France

Received 27 January 2009; accepted 31 March 2009

Keywords: Streptococcus pneumoniae; Penicillin susceptibility; New breakpoints; Invasive disease; Germany

* Corresponding author. Tel.: +49 241808 9946; fax: +49 2418082483.

E-mail address: mimoehl@ukaachen.de (M. Imöhl). 


\section{Abstract}

Continuous nationwide surveillance of invasive pneumococcal disease (IPD) has been conducted in Germany. From 1992-2008, 12 137 IPD isolates were collected, including 2201 isolates (18.1\%) from patients with meningitis and 9936 isolates (81.9\%) from nonmeningitis cases. Data on penicillin susceptibility were available for 11814 invasive isolates. Categorisation of penicillin susceptibility according to the former Clinical and Laboratory Standards Institute (CLSI) guidelines resulted in $4.3 \%$ intermediate and $1.2 \%$ resistant isolates. When the new CLSI 2008 guidelines are applied, considerably higher resistance rates are observed in the meningitis group (6.5\% resistant) than among the non-meningitis cases $(0.0 \%$ resistant, $0.3 \%$ intermediate). 


\section{Introduction}

Streptococcus pneumoniae is a leading pathogen in bacterial pneumonia, sepsis and meningitis worldwide [1]. Penicillin is still the preferred antimicrobial agent for susceptible S. pneumoniae infections. In January 2008, new breakpoints were published by the Clinical and Laboratory Standards Institute (CLSI) to be used for defining penicillin non-susceptibility of invasive isolates.

The former breakpoints for penicillin were based on concentrations that could be reached in cerebrospinal fluid and the minimum inhibitory concentration (MIC) considered necessary for successful treatment. The new breakpoints are the result of accumulated evidence for successful treatment of patients with pneumococcal infections, even when the isolates showed reduced susceptibility in vitro [2].

Under the former criteria, susceptible, intermediate and resistant breakpoints (MICs) for penicillin were $\leq 0.06,0.12-1 \mathrm{and} \geq 2 \mu \mathrm{g} / \mathrm{mL}$, irrespective of clinical syndrome, route of penicillin administration or point of origin of the pneumococcal isolate. These breakpoints remain unchanged for patients treated with oral penicillin in the new guidelines [2]. Furthermore, according to the new guidelines [2] different breakpoints for parenteral use of penicillin with regard to meningitis and non-meningitis cases have to be applied. In nonmeningitis cases the new breakpoints are $\leq 2,4$ and $\geq 8 \mu \mathrm{g} / \mathrm{mL}$, respectively. For meningitis cases no intermediate category exists; isolates are categorised as susceptible $(\leq 0.06 \mu \mathrm{g} / \mathrm{mL})$ or resistant $(\geq 0.12 \mu \mathrm{g} / \mathrm{mL})$ (Table 1$)$. 
The aim of this study was to evaluate penicillin susceptibility of all $S$. pneumoniae isolates from invasive pneumococcal disease (IPD) sent to the German National Reference Center for Streptococci (NRCS) between 1992 and 2008 and to evaluate potential differences in susceptibility categorisation when applying the new [2] and old CLSI guidelines, respectively.

\section{Materials and methods}

\subsection{Study design}

The NRCS has carried out surveillance for IPD in Germany since 1992. In the current study, a population- and laboratory-based approach was used to collect data regarding IPD in Germany. Isolates were sent to the NRCS by diagnostic microbiology laboratories throughout Germany on a voluntary basis. Cases from 1 January 1992 to 31 December 2008 were included in this study. A case of IPD was defined by the isolation of $S$. pneumoniae from a normally sterile site. In cases of unclear invasiveness, samples were considered to represent invasive disease only after a review of all available laboratory information, specimen type, physician's specialty and comments on request forms. 


\subsection{Microbiological investigations}

Isolates were identified by standard procedures, including bile solubility and optochin sensitivity. MIC testing was performed using the broth microdilution method as recommended by the CLSI and amended from time to time [2]. Streptococcus pneumoniae ATCC 49619 was used as a control strain.

\section{Results}

A total of 12137 isolates from IPD was collected between 1 January 1992 and 31 December 2008. The number of cases for each epidemiological year ( 1 July to 30 June) varied between 225 cases and 1979 cases (mean 656.3 cases). In total, 2201 isolates $(18.1 \%)$ originated from patients with meningitis and 9936 isolates $(81.9 \%)$ were from non-meningitis cases. Data regarding penicillin susceptibility were available for 11814 isolates.

According to the former CLSI guidelines, overall $4.3 \%$ of isolates were intermediate and $1.2 \%$ were resistant to penicillin. When the isolates were classified into meningitis and non-meningitis cases, which is not indicated by the former guidelines, a slightly higher rate of non-susceptibility was observed among the meningitis cases (5.5\% intermediate, $1.0 \%$ resistant) than the non-meningitis group (4.1\% intermediate, $1.2 \%$ resistant). When the new CLSI guidelines are applied, higher resistance rates are detected in the meningitis 
group (6.5\% resistant) than among the non-meningitis cases $(0.0 \%$ resistant, $0.3 \%$ intermediate). When summing up resistance rates from the meningitis and non-meningitis groups, overall $0.2 \%$ of all isolates are intermediate and $1.2 \%$ are resistant to penicillin.

The percentage of all invasive isolates susceptible at 0.06, 1, 2 and $4 \mu \mathrm{g} / \mathrm{mL}$ is shown in Fig. 1, and MICs are illustrated in Fig. 2.

\section{Discussion}

In this paper, we present the results of 17 years of surveillance regarding penicillin susceptibility of IPD in Germany. Whilst the prevalence of antibiotic-resistant $S$. pneumoniae continues to increase worldwide [3,4], in Europe high resistance rates for penicillin have been reported from France, Spain and Eastern European countries. Germany and the Northern European countries are affected to a lesser extent [5]. All isolates associated with meningitis that were formerly categorised as intermediate are now categorised as resistant under the new CLSI guidelines, leading to higher resistance rates. In contrast, considerably lower resistance rates result for non-meningitis cases. Similar data have been published recently from the USA on the basis of a higher underlying level of resistance [6]. 
Finally, application of the new guidelines results in a lower overall rate of penicillin-resistant pneumococcal isolates owing to the numerical predominance of non-meningitis cases. This should be kept in mind when interpreting surveillance studies on pneumococcal penicillin resistance.

Acknowledgements: The authors thank the microbiological laboratories in Germany for their co-operation and for providing the isolates.

Funding: This study was supported in part by Wyeth Pharma GmbH, Germany.

Competing interests: RRR has acted as an advisor for GSK, Wyeth and Aventis Pasteur MSD; since 2007 he is an employee at Wyeth Vaccines Research.

Ethical approval: Not required; epidemiological study. 


\section{References}

[1] Austrian R. Pneumococcus: the first one hundred years. Rev Infect Dis 1981;3:183-9.

[2] Clinical and Laboratory Standards Institute. Performance standards for antimicrobial susceptibility testing. Eighteenth informational supplement. Document M100-S18. Wayne, PA: CLSI; 2008.

[3] Jacobs MR, Good CE, Beall B, Bajaksouzian S, Windau AR, Whitney CG. Changes in serotypes and antimicrobial susceptibility of invasive Streptococcus pneumoniae strains in Cleveland: a quarter century of experience. J Clin Microbiol 2008;46:982-90.

[4] Livermore DM. Bacterial resistance: origins, epidemiology, and impact. Clin Infect Dis 2003;36(Suppl 1):S11-23.

[5] Reinert RR. Pneumococcal conjugate vaccines-a European perspective. Int J Med Microbiol 2004;294:277-94.

[6] Centers for Disease Control and Prevention (CDC). Effects of new penicillin susceptibility breakpoints for Streptococcus pneumoniae_United States, 2006-2007. MMWR Morb Mortal Wkly Rep 2008;57:1353-5. 
Table 1

Clinical and Laboratory Standards Institute (CLSI) breakpoints for Streptococcus pneumoniae

\begin{tabular}{|c|c|c|}
\hline & Susceptible $(\mu \mathrm{g} / \mathrm{mL})$ & Intermediate $(\mu \mathrm{g} / \mathrm{mL}) \quad$ Resistant $(\mu \mathrm{g} / \mathrm{mL})$ \\
\hline \multicolumn{3}{|c|}{ Pre-2008 penicillin interpretations for $S$. pneumoniae } \\
\hline & $\leq 0.06$ & $0.12-1^{a}$ \\
\hline \multicolumn{3}{|c|}{2008 and 2009 penicillin interpretations for S. pneumoniae } \\
\hline Parenteral, non-meningitis & $\leq 2$ & $\geq 8$ \\
\hline Parenteral, meningitis & $\leq 0.06$ & $\geq 0.12$ \\
\hline Oral & $\leq 0.06$ & $0.12-1$ \\
\hline
\end{tabular}

\footnotetext{
${ }^{a}$ High doses of intravenous penicillin (e.g. $\geq 2$ million units every $4 \mathrm{~h}$ in adults with normal renal function) are effective in treating pneumococcal pneumonia due to strains in the intermediate category.
} 
Fig. 1. Percentage of isolates susceptible at $0.06,1,2$ and $4 \mu \mathrm{g} / \mathrm{mL}$ of all invasive isolates, $1992-2008(n=11814)$.

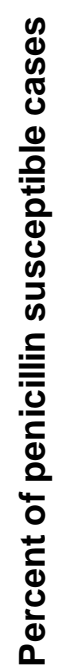

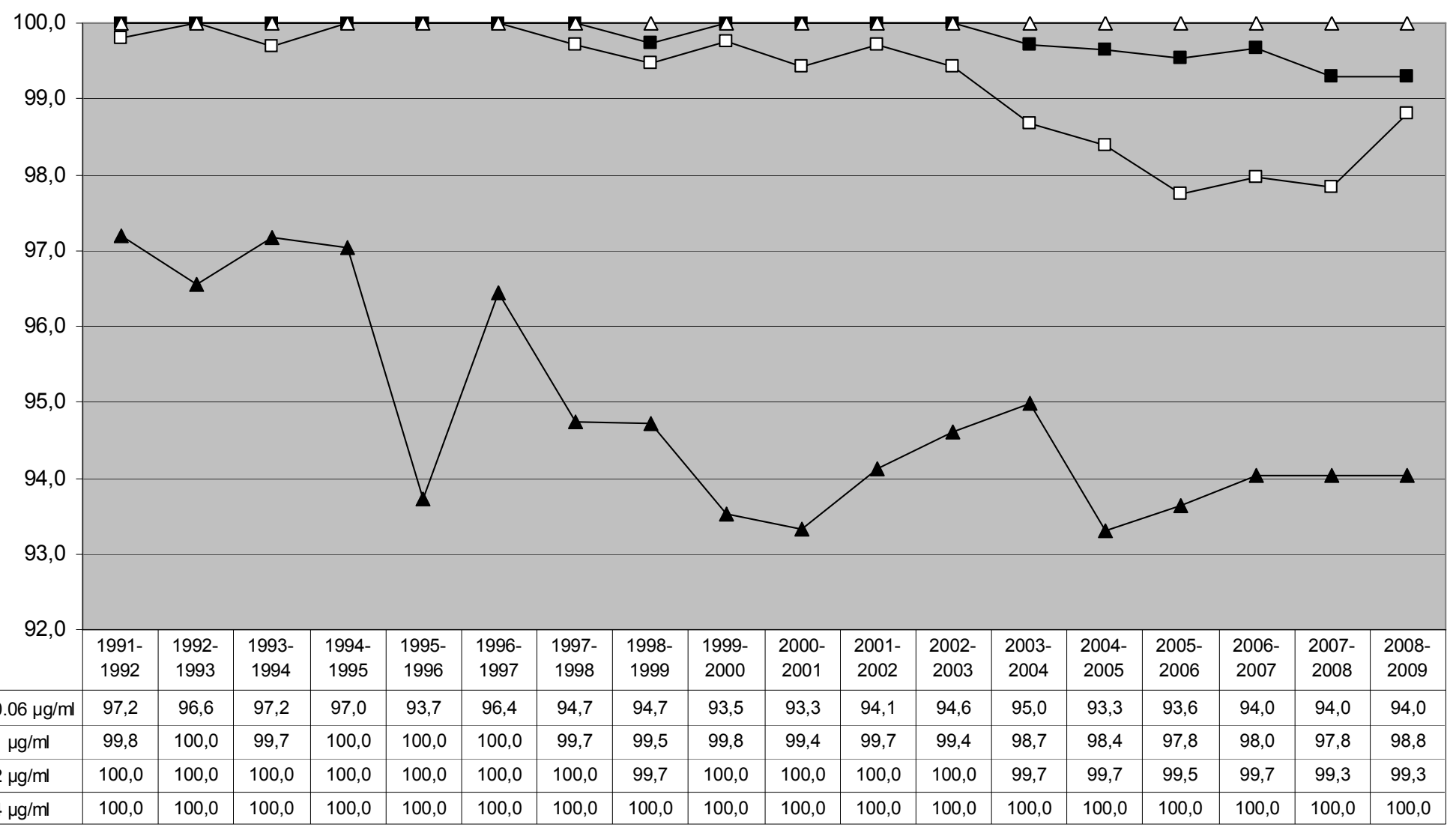

\section{Epidemiological years}


Fig. 2. Minimum inhibitory concentrations (MICs) of all invasive isolates, 1992-2008 $(n=11814)$.

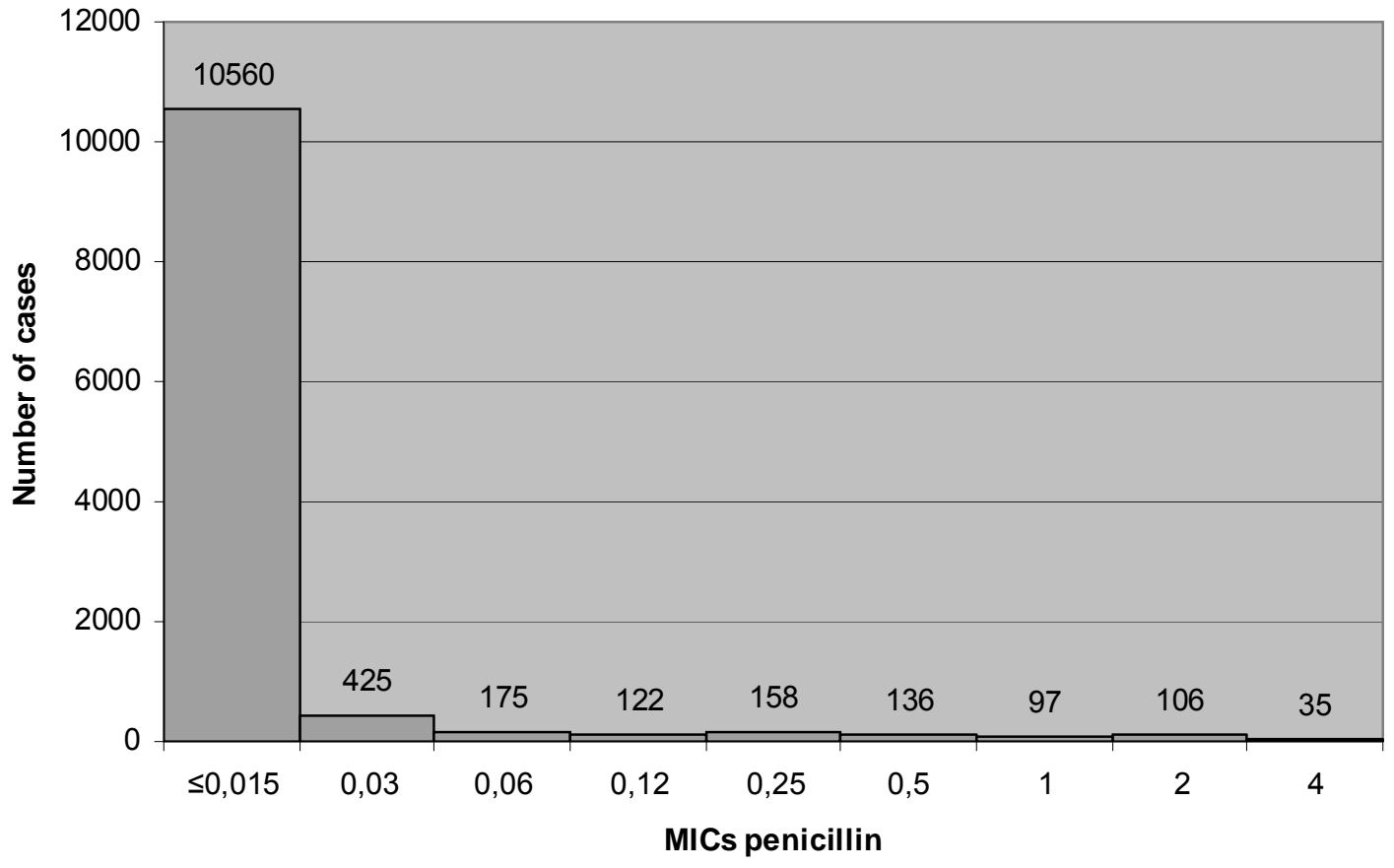


